\title{
A queda do reitor João Alfredo: ação midiática conservadora e a repressão aos dirigentes universitários no Golpe de 1964
}

Dimas Brasileiro Veras ${ }^{1^{*}}$

${ }^{1}$ Instituto Federal de Educação, Ciência e Tecnologia de Pernambuco, Recife/PE - Brasil

\section{RESUMO}

Este artigo analisa o impacto do golpe de Estado de 1964 na educação superior brasileira através da repressão de dirigentes universitários. Em vista disso, investigaram-se os processos políticos que condicionaram o afastamento de reitores naquele ano e, mais precisamente, na renúncia do reitor João Alfredo da Universidade do Recife (UR), atual Universidade Federal de Pernambuco (UFPE). Buscou-se assim identificar as modalidades de organizaçáo e de ação, especialmente midiáticas, utilizadas por grupos e por intelectuais conservadores liderados por Gilberto Freyre nas disputas pela hegemonia do campo universitário em tempos de ditadura militar no Brasil. Para esta pesquisa foram examinadas as Atas do Conselho Universitário, jornais de grande circulação, entrevistas de história oral e os relatórios da Comissão Nacional de Verdade e da Comissão de Memória e Verdade Dom Hélder Câmara.

Palavras-chave: Golpe de 1964; universidade; reitor João Alfredo; Gilberto Freyre; repressão.

\section{The fall of Rector João Alfredo: conservative media action and the repression of university leaders in the 1964 Coup}

\author{
ABSTRACT \\ This article analyzes the impact of the 1964 coup d'état on Brazilian higher education \\ through the repression of university leaders. It investigates the political processes that \\ conditioned the removal of rectors that year and the resignation of the rector João Alfredo of \\ the Universidade do Recife (UR), currently Universidade Federal de Pernambuco (UFPE). \\ The goal of this study is to identify the modalities of organization and action, especially \\ DOI: http://dx.doi.org/10.1590/2237-101X02204611 \\ Artigo recebido em 8 de outubro de 2019 e aceito para publicação em 18 de junho de 2020. \\ * Professor do Instituto Federal de Educaçáo, Ciência e Tecnologia de Pernambuco / Departamento Aca- \\ dêmico de Formação de Professores e Cultura Geral, Recife/PE - Brasil. E-mail: dimasveras@gmail.com. \\ ORCID: https://orcid.org/0000-0002-4684-305X.
}


media, used by conservative groups and intellectuals led by Gilberto Freyre in disputes over the hegemony of the university during the military dictatorship. This research is based on University Council Minutes, widely-circulated newspapers, oral history interviews, and the reports of the National Truth Commission and the Dom Hélder Câmara Memory and Truth Commission.

Keywords: 1964 coup d'état; university; Rector João Alfredo; Gilberto Freyre; repression.

\section{La caída del Rector Joáo Alfredo: acción mediática conservadora y la represión a los dirigentes universitarios en el Golpe de 1964}

\section{RESUMEN}

Este artículo analiza el impacto del golpe de Estado de 1964 en la educación superior brasileña a través de la represión de dirigentes universitarios. En este sentido, se investigan los procesos políticos que condicionaron la retirada de rectores en ese ańo, y, precisamente, en la renuncia del rector João Alfredo de la Universidade Federal de Pernambuco (UFPE). Se busca así, identificar las modalidades de organización, y de acción, especialmente mediáticas, utilizadas por los grupos y por los intelectuales conservadores liderados por Gilberto Freyre en las disputas por la hegemonía del campo universitario en tiempo de la dictadura militar en Brasil. Para esta investigación fueron examinadas las Actas del Consejo Universitario, periódicos de amplia circulación, entrevistas de historia oral y los informes de la Comisión Nacional de la Verdad y de la Comisión de la Memoria y Verdad Don Hélder Câmara.

Palabras clave: Golpe de 1964; universidad; Rector João Alfredo; Gilberto Freyre; represión.

Em dezembro de 1963 o clima político do Brasil se tornara um barril de pólvora. Com o governo federal cada vez mais próximo das esquerdas, a grande imprensa marchara em bloco para a oposição. O presidente João Goulart e o movimento de reforma de base (reforma agrária, eleitoral, urbana, universitária, dentre outras) se afirmavam, então, como centro gravitacional das esquerdas, à medida que o golpe se tornava a palavra de ordem das direitas civis e militares (FERREIRA; GOMES, 2014).

No meio educacional, a militância progressista convergia para o movimento de reforma universitária e para as frentes nacionais de alfabetização em ascensão desde os tempos do Movimento de Cultura Popular (MCP). O MCP fora criado em 1960, durante a gestáo da prefeitura do Recife de Miguel Arraes (1959-1962), por intelectuais e artistas ligados a um braço progressista da Igreja Católica e do Partido Comunista Brasileiro (PCB). Logo 
surgiram outros movimentos de educação e de cultura popular como o Centro Popular de Cultura da União Nacional dos Estudantes (CPC/UNE), o Serviço de Extensão Cultural da Universidade do Recife (SEC/UR), o Movimento de Educação de Base da Conferência Nacional de Bispos do Brasil (MEB/CNBB) etc. (VERAS, 2012). Essas organizaçóes e seus colaboradores foram os principais alvos das graves violaçóes dos direitos humanos nos meios educacionais e culturais perpetrados no contexto do golpe de 1964 (BRASIL 2014a, 2014b, 2014c; BRAYNER; BARBOSA, 2017; VERAS, 2018b).

Neste trabalho a proposta é investigar a repressão no campo universitário durante o golpe civil e militar de 1964 e, mais especificamente, as modalidades de organização e de ação, sobretudo midiáticas, utilizadas por grupos e por intelectuais conservadores liderados por Gilberto Freyre nos processos que condicionaram a coerção e a renúncia do reitor João Alfredo $^{1}$ da Universidade do Recife (UR), atual Universidade Federal de Pernambuco (UFPE). A documentação elencada pela metodologia de biografia geral da elite de dirigentes universitários (BOURDIEU, 2007, 2013; CHARLE, 1994, 2018) assinala o ambiente violento e arbitrário de disputas políticas e acadêmicas em contextos autoritários, integrando o acervo jornais, atas do conselho universitário, processos administrativos, entrevistas de história oral e relatórios das comissóes nacional e regional da verdade.

Quando o reitor João Alfredo convidou, em 1962, o educador Paulo Freire para criar o SEC, a impressão da intelectualidade estabelecida da região era um misto de medo, desconfiança e ódio. Desde o malogro no concurso para Cátedra de Filosofia e História da Educação da Escola de Belas Artes de Pernambuco (EBAPE), em 1960, que o educador dirigia o Setor de Educação do MCP. Ali desenvolvia uma pedagogia cujo método inovador de letramento e conscientização abolia as famosas cartilhas de alfabetização. $\mathrm{Na}$ época, Paulo Freire e sua equipe executavam três programas pilotos: o Sistema Paulo Freire de Educação (VERAS, 2013), a Rádio Universidade (VERAS, 2015) e a Revista Estudos Universitários (VERAS, 2016). Para isso, mantiveram diálogo permanente com o MCP e outros movimentos sociais, desse modo erigindo uma práxis libertadora que fundamenta desde entáo o campo da Educação Popular (VERAS, 2018b).

Essa articulação com grupos populares e de esquerda era visto com desconfiança pelas elites culturais dominantes, as quais eram anticomunistas (MOTTA, 2000). Por esse ângulo o professor Paulo Rosas lembra que ao comunicar sua saída do Centro Regional de Pesquisas Educacionais do Recife do Instituto Nacional de Estudo Pedagógicos (CRPER/INEP) ${ }^{2}$ para

\footnotetext{
${ }^{1}$ João Alfredo Gonçalves da Costa Lima nasceu em Surubim, no Agreste de Pernambuco, em 1898, e faleceu em Recife, em 1971. Médico cirurgião formado pela Faculdade de Medicina do Rio de Janeiro (1924). Fundador e professor catedrático da cadeira de Anatomia e Fisiologias Artísticas da Escola de Belas Artes de Pernambuco (EBAPE). Diretor da EBAPE (1948-1949), vice-reitor (1954-1959) e reitor da Universidade do Recife (1959-1964) (VERAS, 2012; SILVA JUNIOR, 2012).

${ }^{2}$ Atual Instituto Nacional de Estudos e Pesquisas Educacionais Anísio Teixeira. A antiga sede do CRPE
} 
atuar na Divisão de Pesquisas do MCP, o diretor daquele órgão, o sociólogo Gilberto Freyre, advertira-o do perigo de se meter com os comunistas (ROSAS, 2003, p. LIX).

É importante recordar, igualmente, que a criação do SEC e a reforma do Estatuto da UR, durante o reitorado do catedrático de Anatomia e Fisiologia Artísticas (1959-1964), promoviam a participação estudantil pelo exercício da extensão e pela representação nos órgãos de administração e direção universitária. Longe de uma concessão da administraçãa, essa mudança era fruto do fortalecimento do movimento de reforma universitária e de uma greve estudantil de repercussão nacional, cujo início se dera através da ocupação do edifício histórico da Faculdade de Direito do Recife (FDR) em maio de 1961 (CÉSAR, 2009). A ocupação fora sufocada por tanques e metralhadoras num melancólico ensaio de 1964, nada obstante o movimento estudantil tenha vencido a batalha política naquela ocasião.

$\mathrm{Na}$ época, o professor e médico João Alfredo criou uma Comissão para debater as reivindicaçôes discentes, tendo sido inclusive convidado para compor a programação do I Seminário de Reforma Universitária da UNE (VERAS, 2012). Do evento realizado em 1961, em Salvador, seria publicada "A declaração da Bahia", que expressava as primeiras reivindicaçóes do movimento de reforma universitária brasileiro (CUNHA, 2007).

A trajetória biográfica do catedrático da EBAPE tem suscitado diferentes interpretaçôes dos pesquisadores. Uma parte desses trabalhos entende o programa de universidade popular da UR como um espectro acadêmico do populismo e do patrimonialismo. Esse olhar sublinha a manipulação e a cooptação do reitor e seu grupo político, através do Serviço de Extensão Cultural, sobre professores, administrativos e estudantes (PERRUCI, 1986; SILVA JUNIOR, 2012). Como se poderá ver, essa tese corrobora, em suas devidas proporçôes, as denúncias anticomunistas que resultaram na prisão dos membros do SEC e na renúncia de João Alfredo.

Numa outra perspectiva, procurou-se mapear a teia ziguezagueante do ambiente acadêmico e cultural que circulou o golpe. $\mathrm{O}$ problema direcionava-se, desse modo, às multiplicidades históricas através das quais os professores, os estudantes, os administrativos, dentre outros colaboradores, atribuíram diferentes sentidos à universidade e se mobilizaram, acionando recursos desiguais, em defesa de seus interesses e desejos. Nesse caso, a manutenção do status quo acadêmico convive com as linhas de fuga que arrastam a comunidade universitária para o redemoinho político e cultural dos anos 1960 (TEIXEIRA, 2007; VERAS, 2012).

As escolhas do reitor João Alfredo tiveram diferentes repercussōes entre sua primeira eleição em 1959, a reeleição em 1962 e, finalmente, a renúncia em 1964³. À vista disso, à

abriga hoje um dos edifícios da Fundação Joaquim Nabuco (FUNDAJ).

${ }^{3}$ Sobre a dinâmica de nomeação de reitores, cabe observar que o tema ganhou destaque recentemente devido às intervençôes do Ministério da Educação (MEC) nas reitorias das Universidade Federais e dos Institutos Federais, a despeito da consulta comunitária prévia e da lista tríplice prevista pela legislação. De 2019 a 2020, o governo do presidente Jair Messias Bolsonaro interveio em pelo menos dez instituiçôes federais de ensino (MORENO, 2019; GOMES, 2020). 
medida que se posicionava no campo das esquerdas, também possuía fluência nos demais polos políticos. Essa relação se azeda parcialmente no final de 1963, quando é tragado pela ampla coalizão de oposição que se mobilizava pela deposição de João Goulart e de seus aliados. Embora o ambiente não fosse inicialmente favorável, devido à bandeira da legalidade democrática e às tentativas frustradas de golpe, os grupos liberais e conservadores buscavam se reorganizar em todos os meios sociais, inclusive no intelectual.

Com efeito, uma série de iniciativas antidemocráticas fizeram do Recife epicentro da campanha autoritária no Norte e Nordeste do Brasil, como indica Dreifuss em sua tese sobre a participação do Instituto Brasileiro de Ação Democrática (IBAD - 1959-1963) e do Instituto de Pesquisa e Estudos Sociais (IPES - 1962-1972) no golpe de Estado de 1964 (DREIFUSS, 1981). A dita "ação ideológica e social" de classes e grupos dominantes consistia em atividades de mobilização, de divulgação e de desinformação com fins de fortalecimento do programa das direitas e de desestabilização da agenda reformista popular. Dentre os grupos a serem freados no âmbito da educação se encontravam o Instituto Superior de Estudos Brasileiros (ISEB), a UNE, o MCP, o CPC, o SEC, entre outros (SOUZA, 1981). É nessa lógica que se compreendem as lutas travadas no campo educacional do Recife entre o MCP e o Serviço de Promoção Social (SPS), uma sucursal do IBAD (BATISTA NETO, 1987), bem como a sanha repressiva que envolveu o SEC e o reitor João Alfredo.

De outro modo, o crescimento da frente popular no início dos anos 1960 ampliou os canais de comunicação das esquerdas com as organizaçôes estudantis e com a Universidade do Recife. Do ponto de vista político regional este deslocamento é inseparável do fortalecimento da Frente do Recife, coligação de esquerda que conduzira Miguel Arraes à prefeitura do Recife (1960-1963) e ao Governo do Estado (1963-1964), da presença marcante da Superintendência do Desenvolvimento do Nordeste (SUDENE) e de seu idealizador, Celso Furtado, tanto quanto dos movimentos sociais do campo e da cidade: as ligas camponesas, os sindicatos rurais e urbanos, as associaçôes comunitárias e de bairro, os movimentos de educação e cultura popular, o movimento estudantil etc. (TEIXEIRA, 2007; VERAS, 2012).

Ademais, o professor João Alfredo contava com o apoio político de seu genro, o deputado federal Artur de Lima Cavalcanti ${ }^{44}$, do Partido Trabalhista Brasileiro (PTB), cujo prestígio favoreceu a relação entre a reitoria e a capital nacional; "foi seu braço político", como recorda a professora Maria Antônia Mac Dowell (MAC DOWELL, 2012, p. 235-236).

É importante o esclarecimento de que isso não significa que o reitor João Alfredo fosse um homem de esquerda. Assumira, no entanto, uma posição progressista por força do ambiente e das alianças políticas estabelecidas (VERAS, 2012). A própria forma de lidar com os estudantes mudara, como revela, por exemplo, o gesto de abdicar, naqueles anos, da cultura

\footnotetext{
${ }^{4}$ O político elegera-se primeiramente vice-prefeito (1960-1963) de Miguel Arraes pela Frente do Recife. Desfrutava, então, o capital político do seu tio, Carlos de Lima Cavalcanti, interventor federal (1930-1935) e governador de Pernambuco (1935-1937) (ABREU, 2010).
} 
dos catedráticos de não falar com o alunado:

Joaquim Amazonas, por exemplo, como comentava os antigos, não falava com estudante [...] Quando papai morreu, ele veio do aeroporto direto lá pra casa. Ele falou com mamãe, falou com minha irmã, falou com meus dois irmãos e não falou comigo porque eu era estudante da universidade [...]. Já o reitor João Alfredo, não. João Alfredo era simpático, cordial mesmo. Muito diferente. Falava com todo mundo (MOREIRAS, 2012, p. 38).

A disposição política do reitor se motivara igualmente no diálogo com Paulo Freire e sua nascente pedagogia, da qual era apoiador desde os tempos em que dirigira o professor de educaçáo na Escola de Belas Artes de Pernambuco (EBAPE), entre os anos de 1955 e 1959. João Alfredo não viveu o suficiente para ver que sua aposta não fora em vão, afinal parte de sua queda se motivara na abertura da universidade às ideias do futuro Patrono da Educação Brasileira (Lei no 12.612, de 13 de abril de 2012) e um dos autores mais citados no mundo (o terceiro mais citado no ano de 2016), de acordo com as pesquisa do professor Eliot Green, do Development Studies in the Department of International Development at the London School of Economics (GREEN, 2016) e do Open Syllabus Explorer, da Universidade de Columbia (OPEN SYLLABUS, 2020).

Por outro lado, considerando a heteronomia da universidade brasileira em relação ao Estado, a boa relação política com o Governo Federal, Estadual e Municipal era imprescindível para concretizar o programa de gestão do antigo diretor da EBAPE, a despeito de sua posição política. Outrossim, o posicionamento do reitor se respaldava, além disso, numa fração de professores e administrativos que colaboravam com o campo de esquerda no estado (BARBOSA, 2011).

Devido às suas posiçóes e às relaçóes que mantinha, o professor João Alfredo tornou-se, naqueles anos, alvo de uma guerra midiática, articulando não só os militares, mas notadamente seus aliados civis na grande imprensa e no meio intelectual, sob a liderança do consagrado sociólogo Gilberto Freyre. Para tal fim, apropriaram-se dos meios de comunicação para reivindicar um corpo social brasileiro limpo, desinfetado, expurgado, saneado, higienizado, que resultou, nesse caso, na queda do catedrático.

Essa campanha política e moral se deu através de uma parafernália de signos, de práticas e de organizações sociais e subjetivas com fins de eliminação dos concorrentes e de controle das agências institucionais e de seus fluxos. A ação jornalística partia de chamadas multimídias redundantes, cujo apelo ao senso comum e às emoções compostas de medo, raiva, tristeza, nojo, dentre outras, atravessam o corpo como armas de guerra, acionando gatilhos de "perceptos" e de "afectos" que expressam e mobilizam sentimentos mais complexos, como o ódio e a intolerância (DELEUZE; GUATTARI, 1992, 1997), tal qual, mutatis mutandi, o fenômeno presente das fake news ${ }^{5}$ (OBERCOM, 2018; DELMAZO; VALENTE, 2018).

\footnotetext{
${ }^{5}$ Compreende-se o fenômeno como uma modalidade de ação midiática pela internet que visa à distorção
} 
As fontes sugerem, em consonância com o aporte teórico metodológico, que a polarização da época ganha uma dimensão própria na universidade, isto é, as posiçôes políticas gerais dos agentes universitários são igualmente condicionadas pelas disposiçôes da política acadêmica (CHARLE, 1994, 2018; BOURDIEU, 2013; MOTTA, 2014). A constante referência às verbas, empregos, prestígio, órgãos e a outros recursos da universidade mostram que os ataques anticomunistas e moralistas são inseparáveis da luta pela conquista de espaços de produçáo acadêmica, tanto pelo que representam, quanto pelo que mobilizam. Afinal, essas instâncias de poder hierarquizado possibilitam o controle das unidades administrativas adjacentes e de seus fluxos: recrutamentos, cursos, currículos, exames, programas didático-científicos, publicaçôes, livros, discursos científicos, diplomas, espaços físicos, laboratórios, equipamentos, transporte, enfim, toda fluidez da máquina universitária.

Nessa perspectiva, um grupo de intelectuais vinculados às instituiçóes culturais e educacionais do Recife iniciaram uma guerra contra a revista Estudos Universitários do SEC e seu programa educacional paulofreireano. Sobre essa história é importante recordar a influência final de Gilberto Freyre e da professora Maria do Carmo Tavares de Miranda ${ }^{6}$ para o empastelamento do periódico e para a demissão de seu redator, o crítico Luiz Costa Lima, em dezembro de 1963 (VERAS, 2012).

A inauguração definitiva da Rádio Universidade, também pelo SEC, fez da estação o novo alvo daquele grupo chamado por Paulo Rosas de "intelectuais conservadores prudentes". O grupo estabelecera-se nas principais instituiçôes culturais do estado, como o Centro Regional de Pesquisas Educacionais do Recife (CRPER/INEP) ${ }^{8}$, o Instituto Joaquim Nabuco de Pesquisas Sociais (IJNPS) ${ }^{9}$, o Gabinete Português de Leitura, a Academia Pernambucana de Letras, o Instituto Arqueológico, Geográfico e Histórico de Pernambuco (IAGHPE), o Arquivo Público Estadual, o Gabinete Português de Leitura e a Universidade do Recife (ROSAS, 2003, p. LVII).

Para essa família letrada, urgia defender as posiçôes institucionais conquistadas nas últimas décadas, do mesmo modo que preservar uma prática intelectual nutrida na cultura tradicional brasileira, em suas matrizes luso-tropicais. Embora não desconsiderassem os problemas das classes trabalhadoras e populares, essa intelligentsia propunha o enfrentamento

deliberada de conteúdos com fins de desinformação, (des)mobilização e de desvalorização de práticas, de instituiçóes e de agentes sociais, em meio a um ambiente argumentativo permeado pelo apelo emocional e econômico das redes sociais (os likes e os clickbaits) e pela crise da imprensa tradicional e da ciência (a dita pós-verdade).

${ }^{6}$ Professora ligada à "Marcha com Deus pela Família" e primeira colocada em concurso para a cátedra de Filosofia e História da Educação, disputado com Paulo Freire em 1959.

${ }^{7}$ Grupo liderado por Gilberto Freyre e integrado por professores prestigiados, como Newton Sucupira, Jordão Emerenciano, Gilberto Osório, José Antonio Gonsalves de Mello, Maria do Carmo Tavares de Miranda, dentre outros.

${ }^{8}$ Vinculado ao Instituto Nacional de Estudos Pedagógicos (INEP - atual Instituto Nacional de Estudos e Pesquisas Educacionais Anísio Teixeira).

${ }^{9}$ Atual Fundação Joaquim Nabuco (FUNDAJ). 
das injustiças sociais por meio de soluçôes conciliadoras que conservassem o status quo. A crescente aproximação da Reitoria da UR com o bloco reformista, os "intelectuários", como Gilberto Freyre chamava as fraçóes letradas de esquerda, com o programa do SEC e com a nomeação de Paulo Rosas para direção do recém-inaugurado Instituto de Ciências Humanas da UR (ICH) ${ }^{10}$ mergulhou a Universidade no torvelinho de conflitos que arrastou pelo ralo a ordem constitucional estabelecida em 1946 (VERAS, 2018b).

No geral as denúncias anticomunistas e moralistas contra o SEC e a Reitoria partiram do Diário de Pernambuco, na época principal veículo de comunicação das classes e de grupos dominantes da regiáo. ${ }^{11}$ Se no final da contenda o coro de delaçôes se concentrou na voz de Gilberto Freyre, antes disso ecoou entre as colunas "Periscópio" e "Informativo Econômico". As seçôes de economia e política do jornal eram assinadas, respectivamente, pelos jornalistas Paulo Malta e Marcos Aurélio da Alcântara, dois reconhecidos porta-vozes da autodenominada "classe conservadora" do estado (usineiros, senhores de engenho e banqueiros).

A campanha midiática se apoiava em informaçôes distorcidas e falsas sobre o programa radiofônico de alfabetização no "Sistema Paulo Freire" mantido pelo MCP e pelo Movimento de Educação de Base da Conferência Nacional de Bispos do Brasil (MEB) na Rádio Universidade. O programa "Campanha de Alfabetização" divulgava os desdobramentos do Programa Nacional de Alfabetização (Decreto no 53.465, de 21 de janeiro de 1964) e da Comissão de Cultura Popular, dirigidos respectivamente pelos professores Paulo Freire e Jomard Muniz de Britto (VERAS, 2015). Segundo a coluna "Informativo Econômico", "pontas avançadas do esquerdismo" e "comunismo" promovidos com "apoio e incentivo do magnífico reitor".

Essas ações de desinformação jornalística sempre faziam largo uso do léxico anticomunista tão em voga na Guerra Fria: "proselitismo marxista-leninista", "batalha da conquista ideológica", "guerra psicológica", "subversão", dentre outros. Os signos da intolerância política e cultural são costurados amiúde com advertências que estimulam a paranoia e o ódio: "Não digam os democratas, quando perderem, definitivamente, o poder político no Brasil, que a campanha era surda e traiçoeira". ${ }^{12}$

Diante das malsinaçôes, o reitor não tardou em sair em defesa da Rádio Universidade. Nesse sentido, esclareceu que a campanha de alfabetização do MEB e do MCP nâo se utilizava da estaçấo universitária, desmentindo as notícias falsas sobre uso de "cartilha [...] pregando a luta de classe", uma vez que o "sistema Paulo Freire" abdicara dos abecedários

\footnotetext{
${ }^{10}$ A partir de 1974 é fundido com a antiga Faculdade de Filosofia de Pernambuco, passando-se a se chamar Centro de Filosofia e Ciências Humanas (CFCH).

${ }^{11}$ O Diário de Pernambuco pertencia aos Diários Associados, conglomerado midiático criado e presidido na época pelo magnata Assis Chateaubriand, tendo o grupo apoiado o golpe civil e militar de 1964 e assumido posição ambígua de adesão e oposiçáo ao regime militar de acordo com seus interesses variados.

${ }^{12}$ ALCÂNTARA, Marcos Aurélio. Informativo Econômico. Diário de Pernambuco, 19 dez. 1963, p. 4. No original do jornal o autor assina "M.A.A.".
} 
em favor dos círculos de cultura. Sobre a "Campanha de alfabetização", explicava que o programa diário de apenas 15 minutos visava divulgar os desdobramentos do Plano Nacional de Alfabetização e da Comissão de Cultura Popular. Para orgulho do reitor tais iniciativas nacionais se baseavam na experiência institucional do SEC. ${ }^{13}$

Talvez ele não ignorasse que ali estava justamente a principal fonte de toda a discórdia. Dessa forma, o colunista do Diário de Pernambuco seguia alardeando a suposta "orientaçáo facciosa e comunista", de "propaganda subversiva" e de "técnica subliminar de propaganda" próprias ao $\mathrm{MCP}$, ao SEC e à UNE..$^{14} \mathrm{Da}$ mesma maneira volta a impingir novas ofensivas em matéria do dia primeiro de janeiro quanto à "omissão do Magnífico reitor" em "substituir os redatores do programa e limpar o Serviço dos seus elementos mais radicais". Imputava-lhe, por conseguinte, a reponsabilidade pela corrupçáo moral e política do presidente do DCE, que se posicionara, desde o princípio da contenda, em defesa do SEC: "distinto jovem, até há pouco tido como bom moço". ${ }^{15}$

Numa segunda parte do texto, o Informativo Econômico colocara-se como porta voz da insatisfação de dirigentes acadêmicos no que concerne ao repasse de recursos federais para o SEC em suposto detrimento das unidades de Medicina, Geologia, Engenharia, Antibióticos e Micologia, primeiros institutos de pesquisa da UR. Alude a supostas práticas de corrupção contidas num "Relatório Azul" com demonstrativo de despesas universitárias de pessoal "muito acima do admissível". Ainda mais acusa a pedagogia Paulo Freire de plágio. Conclui, finalmente, caluniando a cooperaçáo estabelecida entre a reitoria da UR e os movimentos sociais para expandir o programa de educação popular na Zona da Mata: "Tudo, para conseguir o processo de libertação do nosso povo: com gordas verbas federais, bons empregos, prestígio e carro oficial. Às custas da Reitoria”. ${ }^{16}$

Em nenhum momento a elite de dirigentes universitários se manifestou publicamente para confirmar ou refutar as acusaçóes contra o reitor, apesar da polarização política do momento. O tema foi tratado brevemente no final da reunião do Conselho Universitário pelo vice-reitor Newton Maia. Em tom solidário, o presidente em exercício do Conselho destacou o esforço da gestáo por mais verbas - "movimento no país inteiro" - sob o apoio do presidente do DCE. ${ }^{17}$

Todavia, antes disso, o jornalista Marcos Aurélio de Alcântara costurava outras alianças sem o pudor de expor as conspiraçôes em curso, quando encaminhou as denúncias falsas de "mecenato da reitoria" e "Casamento MCP e Rádio Universidade" recomendando forte-

${ }^{13}$ ALFREDO, João. Esclarecimentos sobre o programa da Rádio Universidade do Recife. Diário de Pernambuco, 22 dez. 1963, p. 9.

${ }^{14}$ ALCÂNTARA, Marcos Aurélio. Informativo Econômico. Diário de Pernambuco, 24 dez. 1963, p. 4.

${ }^{15}$ ALCÂNTARA, Marcos Aurélio. Informativo Econômico. Diário de Pernambuco, 24 dez. 1963, p. 4; 1 jan. 1964, p. 4.

${ }^{16}$ ALCÂNTARA, Marcos Aurélio. Informativo Econômico. Diário de Pernambuco, 1 jan. 1964, p. 4.

${ }^{17}$ UNIVERSIDADE DO RECIFE. Atas do Conselho Universitário da Universidade do Recife. Recife: UR, 12 mar. 1964, [s.p.]. 
mente a leitura ao General Justino Alves Bastos, comandante do IV Exército. ${ }^{18}$ Apenas uma semana depois voltou a assacar a questão orçamentária dos centros universitários, especialmente da Faculdade de Medicina do Recife (FMR), da Faculdade de Ciências Econômicas (FCE) e das bolsas de pós-graduação concedidas pela SUDENE. De forma redundante, as ações pioneiras de ensino, pesquisa e extensão da universidade são comumente associadas à corrupção, à imoralidade e à subversão comunista. ${ }^{19}$

Sem concessões para defesa dos alvos das delaçôes caluniosas, as matérias seguem expondo todo seu ódio ante à Rádio Universidade e aos programas de educação para os camponeses da Zona da Mata. Dessa forma, ao apontar suas referências pedagógicas nos pesquisadores Carlos Frederico Maciel e Tarcísio Rego Quirino, do já citado CRPER/INEP, nas escolas confessionais e no "Sistema $S^{20}$, o jornalista enuncia as pessoas, grupos, classes e instituiçôes que alimentavam sua crítica. ${ }^{21}$

Numa crônica publicada alguns dias depois, o diretor do CRPER soltava quase sem querer o "bom exemplo" do sistema universitário soviético, citando ainda no primeiro parágrafo o caso de dois professores da UR, supostamente recrutados pelo reitor João Alfredo: "Curioso que sua excelência o Sr. embaixador da Uniáo Soviética no Brasil se fizesse acompanhar, em algumas de suas visitas a autoridades, no Recife, de dois ilustres professores universitários da capital Pernambucana". ${ }^{22}$

Entre março e abril as matérias se tornaram cada vez mais virulentas. Sem sucesso, a Rádio Universidade é denunciada dessa vez por ceder espaço em sua programação aos ditos "padres participantes" ou "engajados". Apesar da colaboração de antigos militantes da Juventude Universitária Católica (JUC) e de dois padres da Equipe Paulo Freire, Paulo Gaspar Menezes e Almeri Bezerra, este último vice-diretor do SEC, bem como dos colaboradores do $\mathrm{MEB}$, não há registro que nenhum deles tenha mantido programas na Rádio Universidade. Embebido em suas próprias ficçôes, o jornalista se regozijaria por ocasiáo do golpe de Estado: "A esta altura, acredito que a emissora já tenha sido devidamente ocupada pelas forças do IV Exército [...] interditando também os padres e agitadores que faziam dos microfones a tribuna de sua pregação subversiva e totalitária". ${ }^{23}$

\footnotetext{
${ }^{18}$ ALCÂNTARA, Marcos Aurélio. Informativo Econômico. Diário de Pernambuco, 12 jan. 1964, p. 4. ${ }^{19}$ ALCÂNTARA, Marcos Aurélio. Informativo Econômico. Diário de Pernambuco, 16 jan. 1964, p. 4.

${ }^{20}$ Rede de organizaçóes de treinamento profissional, assistência social, consultoria, pesquisa, extensão e inovação mantida por entidades de classe empresarial com incentivo fiscal do Estado e do trabalhador brasileiro. $\mathrm{Na}$ época, Serviço Social da Indústria (SESI) e Serviço Nacional de Aprendizagem Industrial (SENAI), Serviço Social do Comércio (SESC), Serviço Nacional de Aprendizagem do Comércio (SENAC) e Serviço Brasileiro de Apoio às Micro e Pequeno Empresas.

${ }^{21}$ ALCÂNTARA, Marcos Aurélio. Informativo Econômico. Diário de Pernambuco, 19 jan. 1964, p. 4; 9 fev. 1964, p. 4; 15 fev. 1964, p. 4; 16 fev. 1964, p. 4; 26 fev. 1964, p. 4.

${ }^{22}$ FREYRE, Gilberto. Um bom exemplo russo-soviético. Diário de Pernambuco, 1 mar. 1964, p. 4.

${ }^{23}$ ALCÂNTARA, Marcos Aurélio. Informativo Econômico. Diário de Pernambuco, 10 mar. 1964, p. 4; 14 mar. 1964, p. 4; 22 mar. 1964, p. 4; 3 abr. 1964, p. 4.
} 
Diante da intervenção militar, o reitor João Alfredo tentou se acomodar ao novo ambiente político, de modo a assegurar seu projeto de gestâo e resguardar a universidade de uma possível intervenção. No dia 6 de abril ele comunicou ao General Joaquim Justino Alves Bastos, comandante do IV Exército, sobre a nomeaçáo de Edmir Regis ${ }^{24}$ para dirigir o SEC e a Rádio Universidade, uma vez que os antigos diretores e membros do órgão se encontravam presos ou foragidos. ${ }^{25} \mathrm{Edmir}$ Regis agradeceu publicamente ao reitor pela oportunidade e anunciou uma programação em convênio com o Instituto de Ciências da Informaçáo da Universidade Católica de Pernambuco (UNICAP): "dentro de critérios absolutamente culturais e recreativos". ${ }^{26}$

Ainda no mês de abril um grupo de estudantes liderados por Fernando de Mello Freyre, aluno da FDR e filho primogênito de Gilberto Freyre, visitou a sede do Diário de Pernambuco para exigir das autoridades a saída imediata do reitor João Alfredo. Previamente, o grupo queixou-se do convite enviado ao catedrático para cerimônia da posse do general presidente Castelo Branco e dos "padrinhos" que o mantiveram na reitoria, mesmo após a pretensa "redemocratização do Brasil". ${ }^{27}$

O episódio marcou o retorno de Gilberto Freyre aos embates contra a Reitoria da UR. Com a entrada do sociólogo, o colunista de economia Marcos Aurélio de Alcântara recua temporariamente do conflito, o que sugere implicitamente a ação midiática orquestrada. Logo Gilberto Freyre reivindicou o afastamento do Reitor da UR, tal qual fizera a "revolução" na Universidade Federal da Paraíba (UFPB) e na Universidade de Brasília UNB. Como justificativa, apontou a subversão das "iniciativas nada universitárias ligadas à chamada 'extensão universitária"” e o fato de o reitor não ter publicado nenhuma manifestação pública de apoio à "Revoluçáo" ou de "arrependimento" pelos erros cometidos. Por fim, comemorou a indicação da professora Maria do Carmo Tavares de Miranda para Divisão de Recursos Humanos da Sudene ${ }^{28}$, sua futura candidata a "Reitor-interventor". ${ }^{29}$

Diante da conjuntura adversa, o professor Joáo Alfredo viajou a Brasília para a posse de Castelo Branco e para a reunião com o novo Ministro da Educação, Flávio Lacerda Suplicy. Sua corrida visava de alguma forma reverter as denúncias em curso e se integrar ao governo golpista. Após o retorno, afirmou conciliatoriamente: "Em Brasília encontrei clima de tranquilidade e de esperança, decorrente da confiança que envolve o governo da República sob chefia do Marechal Humberto Castelo Branco". ${ }^{30}$

\footnotetext{
${ }^{24}$ Irmão de Édson Regis, que seria morto no atentado a bomba no Aeroporto Internacional do Recife/Guararapes em 1966. A ação objetivava atingir o general Costa e Silva, então possível sucessor do general presidente Castelo Branco (SANTOS, 2007).

${ }^{25}$ FORÇAS Armadas tem objetivo de descomunizar país. Diário de Pernambuco, 7 abr. 1964, p. 3.

${ }^{26}$ ALUNOS de jornalismo vão estagiar na Rádio Universidade e na A. N. Diário de Pernambuco, 26 abr. 1964, p. 14.

${ }^{27}$ UNIVERSITÁRIOS estranham permanência do reitor. Diário de Pernambuco, 25 abr. 1964, p. 4.

${ }^{28}$ FREYRE, Gilberto. O caso da Universidade do Recife. Diário de Pernambuco, 3 mai. 1964, p. 4.

${ }^{29}$ FREYRE, Gilberto. Justiça revolucionária e universidade. Diário de Pernambuco, 19 jun. 1964, p. 4.

${ }^{30}$ REITOR diz que encontrou em Brasília tranquilidade, esperança e confiança. Diário de Pernambuco, 3 mai. 1964, p. 10.
} 
Simultaneamente, a coluna "Periscópio" retomou as investidas contra a reitoria da UR. Dessa vez para questionar a legitimidade da Comissão de Inquérito da UR nomeada por João Alfredo. Naquele momento, os jornais diziam circular no meio estudantil um manifesto exigindo a renúncia do médico e professor. Os termos do documento publicado no Diário de Pernambuco foram exatamente os mesmos da declaração que Fernando Freyre dera aos jornais. ${ }^{31}$

Ainda na mesma edição, o reitor da Universidade do Recife tentava se defender dos novos ataques. Nesse sentido, citava a reunião realizada em seu gabinete com Gilberto Freyre sobre o Instituto de Ciências Humanas (ICH) e sua Divisão de Antropologia Tropical, do mesmo modo que os recursos extraordinários conquistados através do Convênio MEC/ SEC/UR. Segundo o reitor, seu apoio ao regime era demonstrado mediante o trabalho com fins de "preservar a ordem e a tranquilidade em toda área de ação da Universidade do Recife, após a eclosão do movimento revolucionário, atuação esta reconhecida pelo Comando do IV Exército".32

Desapontado com o pretenso desprezo por sua "boa vontade", tal quais "brasileiros [...] desinteressados de vantagens partidárias ou de proveitos pessoais", Freyre insistiu na "responsabilidade inconfundível" do reitor pelo desvio de função da Universidade e pela permissividade com o que chama de "vergonhosas imundices demagógicas". 33

Por conseguinte, sem ver grandes resultados, o sociólogo radicalizou o discurso, como se percebe no negrito, na caixa alta e no título da matéria: LIMPEZA URGENTE. O então diretor do CRPER destacou o papel dos militares em deter a infiltração comunista. Essa postura se contrasta com o pretenso "acovardamento" dos "fracos reitores", das associaçóes de imprensa, escritores, arquitetos, artistas, educação e da SUDENE. Ao que conclamou a sociedade a denunciar os "ninhos comunistas" e o governo a reprimi-los:

Daí a necessidade de proceder-se agora a uma operação corajosa de limpeza nesses setores. Num, pela ação do novo governo, noutros, pela ação de intelectuais, artistas, estudantes, técnicos não-comunistas que são no Brasil a grande maioria. Onde quer que se tenham constituído, clara ou disfarçadamente, ninhos comunistas empenhados na distorção da cultura brasileira em benefícios de desígnios russo-comunistas ou sino-comunistas, é preciso que esses ninhos sejam destruídos de modo implacável. Sem condescendência de caráter sentimental ou pessoal. Sem panos mornos.

Trata-se de realizar a obra muito mais que profilaticamente destrutiva: brasileiramente construtiva. Culturalmente construtiva. Construção, porém, que exige destruição porque

\footnotetext{
${ }^{31}$ PERISCÓPIO. Diário de Pernambuco, 5 mai. 1964, p. 2; ESTAVA integrado na ação subversiva. Diário de Pernambuco, 5 mai. 1964, p. 8.

${ }^{32}$ REITOR defende-se de críticas à sua atuação na UR. Diário de Pernambuco, 5 mai. 1964, p. 3; UNIVERSIDADE DO RECIFE. Comissöes de Inquérito. Comissão para apurar responsabilidade de servidores docentes/ administrativos (Art. $8^{\circ}$ do Ato Institucional). Recife: UR, 12 jun. 1964, [s. p.].

${ }^{33}$ FREYRE, Gilberto. Uma responsabilidade inconfundível. Diário de Pernambuco, 17 mai. 1964, p. 4.
} 
reclama profilaxias, assepsia, limpeza. Obra de "são brasileirismo", nos diria Sylvio Romero. O momento de ser realizada tal obra é este. Precisamente este. Um momento revolucionário. O que é preciso é que a revolução iniciada a 31 de março não tema ser ou parecer Revolução, pelo receio de desagradar certos liberalóes dos Estados Unidos. Ou da Europa. Ou de Caracas. ${ }^{34}$

As chances de sucesso de João Alfredo se esvaíam a cada nova matéria. Desse modo, o "Informativo Econômico" acenou para o triunfo iminente ao celebrar o avanço da "limpeza e desinfecção" da UR e o do SEC, antiga "base intelectual do proselitismo de esquerda". Naqueles dias Gilberto Freyre acompanhou e discursou ao lado do general presidente Castelo Branco, em palanque montando na Avenida Conde da Boa Vista, principal via do centro do Recife. ${ }^{35}$

Durante a visita de dois dias, o ditador dedicou uma atenção especial ao governador Paulo Guerra e a Gilberto Freyre, apesar da presença de outras autoridades militares e civis, dentre as quais seis governadores. Aliás, conta-se que o general citara duas passagens do livro Nordeste em cerimônia na SUDENE. No entanto, declinou o convite de visitar a sede do IJNPS em Apipucos, para onde enviou o Ministro dos Transportes, Juarez Távora, e o Ministro da Educação, Suplicy de Lacerda.

Durante a visita a Apipucos, os ministros discutiram, entre outros temas, as denúncias de infiltração comunista na Reitoria da UR. De acordo com o titular da pasta de educação, oferecera-se ao reitor a sugestão de que solicitasse licença para afastamento do cargo, ao mesmo tempo que entregara o caso para as autoridades militares do IV Exército e para a Comissão de Inquérito responsável. ${ }^{36}$

Fortalecido com a primeira visita presidencial, o sociólogo desferiu mais um golpe. Publicou uma lista com os nomes dos catedráticos supostamente comprometidos pelos equívocos do reitor João Alfredo: os professores Murilo Guimarães (Faculdade de Direito do Recife), Osvaldo Gonçalves Lima (Instituto de Antibióticos), Gilberto Osório (Faculdade de Filosofia de Pernambuco), Arnaldo Carneiro Leão (Faculdade de Medicina), Maria do Carmo Tavares de Miranda (Faculdade de Filosofia de Pernambuco), Cláudio Souto (ICH) e Telmo Maciel (Faculdade de Ciências Econômicas). Nenhum deles ousou desmentir o mandarim. Depois da última demonstração de força quem negaria, ademais, todo descrédito atribuído à Comissão de Inquérito designada pelo reitor? Quem questionaria a existência de cartas denunciando a presença de "grupo suicida de fanáticos" disfarçados de professores estrangeiros contratados pelo catedrático de Anatomia e Fisiologia Artísticas? ${ }^{37}$ Ninguém, somente o próprio João Alfredo.

\footnotetext{
${ }^{34}$ FREYRE, Gilberto. Limpeza urgente. Diário de Pernambuco, 26 mai. 1964, p. 3.

${ }^{35}$ ALCÂNTARA, Marcos Aurélio. Informativo Econômico. Diário de Pernambuco, 3 jun. 1964, p. 10; CASTELO recebeu consagradora manifestação. Diário de Pernambuco, 6 jun. 1964, p. 1.

${ }^{36}$ ALCÂNTARA, Marcos Aurélio. Informativo Econômico. Diário de Pernambuco, 9 jun. 1964, p. 2; 4.

${ }^{37}$ FREYRE, Gilberto. Ainda a propósito da universidade. Diário de Pernambuco, 7 jun. 1964, p. 4.
} 
Em um último suspiro, o dirigente universitário respondeu às questôes mais recentes e negou, mais uma vez, a suposta interferência nos assuntos políticos da Universidade do seu genro $^{38}$, o ex-deputado Artur Lima Cavalcanti (PTB), que tivera seu mandato cassado e seus direitos políticos suspensos por força do Ato Institucional (AI-1) de 9 de abril de 1964 (ABREU, 2010).

Todo esforço para no dia seguinte assistir novamente ao autor de Casa-Grande \& Senzala e aos analistas político-econômicos do Diário de Pernambuco repetirem uma a uma cada acusação e a sentença peremptória do sociólogo: "a hipocrisia, a falsidade, a covardia de uns tantos outros. Era isso que o Reitor Joáo Alfredo da Costa Lima queria ouvir? Pois ouça". ${ }^{39}$

Na manhã seguinte, dia 12 de junho de 1964, na sala de reunióes da reitoria da UR, na Rua do Hospício, no 619, às 10h30, o reitor João Alfredo abriu, na qualidade de presidente, a $8^{a}$ reunião do Conselho Universitário, órgão de administração maior da instituição. Estavam presentes na reunião 25 conselheiros. Conforme o protocolo, os trabalhos começaram com a leitura, a discussão e aprovação da Ata da sessão anterior. Após esse primeiro momento, o presidente do Conselho informou que convocara a presente reuniáo para anunciar aos demais pares a decisão de afastar-se definitivamente da reitoria. ${ }^{40}$

Em meio ao burburinho dos catedráticos, o presidente do conclave fez uma breve retrospectiva de seus cinco anos de gestão, dentre os quais destacou as açôes de reforma da universidade e a ótima situação financeira da instituição. Além do mais descreveu o trabalho da Comissão de sindicância da UR para apurar crimes cometidos contra o Ato Institucional (AI-1), cujo relatório já se encontrava a caminho do MEC. Esclareceu, nesse seguimento, que foram inseridos nos autos do processo todas as denúncias publicadas nos jornais, considerando a recusa de Gilberto Freyre em depor por suposto motivo de doença. ${ }^{41}$

O presidente agradeceu toda a confiança da comunidade universitária e reafirmou sua decisão, justificando-a na suspeita do governo federal, aliás, comunicada pelo próprio ministro Suplicy durante a visita presidencial. Dando por encerrada a reunião, o reitor se retirou do saláo, acompanhado solenemente por todos os demais conselheiros até os portóes de acesso da reitoria, num emocionante gesto de solidariedade encaminhado pelo professor Sá Barreto. ${ }^{42}$

O golpe de 1964 afastou prontamente seis reitores e impeliu tantos outros a renunciar, o que representava em torno de um quinto das universidades brasileiras, cerca de 25 estabelecimentos. Dentre os reitores depostos, encontram-se Anísio Teixeira, da UNB, o professor Eliseu Paglioli, da Universidade do Rio Grande do Sul (Atual UFRGS), o professor Manuel Paes de Barreto Filho, da Universidade do Espírito Santo (atual UFES), o professor Mário

\footnotetext{
${ }^{38}$ REITOR João Alfredo responde a artigo de Gilberto Freyre. Diário de Pernambuco, 10 jun. 1964, p. 2, 16.

${ }^{39}$ FREYRE, Gilberto. Em torno da resposta de um reitor. Diário de Pernambuco, 11 jun. 1964, p. 4.

${ }^{40}$ UNIVERSIDADE DO RECIFE. Comissöes de Inquérito. Comissäo para apurar responsabilidade de servidores docentes/administrativos (Art. $8^{\circ}$ do Ato Institucional). Recife: UR, 12 jun. 1964, [s. p.].

${ }^{41}$ Idem.

${ }^{42}$ Idem.
} 
Moacyr Porto, da Universidade da Paraíba (atual UFPB), o professor Colemar Natal e Silva, da Universidade de Goiás (atual UFGO) e o professor Ydérzio Luiz Vianna, da Universidade Rural do Rio de Janeiro (atual UFRRJ), tendo sido este último preso na ocasião (MOTTA, 2014, p. 37-48).

Dezenas de dirigentes universitários foram igualmente arrastados pelo expurgo político acionado pela "Operação limpeza" e substituídos por interventores validados pelo Conselho Federal de Educação (CFE), em conformidade com a caserna. Apesar da resistência docente, muitos dirigentes universitários aplaudiram ou se calaram diante das forças golpistas, assim revelando a adesão, a indiferença e o amordaçamento político de parte expressiva do corpo de catedráticos. Como no caso da UR, essas açóes repressivas zelavam por uma certa discrição e pela acomodação de propostas moderadas e de quadros acadêmicos simpáticos e duplos, isto é, civis e militares, conforme estratégia de uma "ditadura envergonhada" (GASPARI, 2014). O reitor João Alfredo seria homenageado em 1971 com a inauguração de auditório homônimo na sede da reitoria da Cidade Universitária, campus Joaquim Amazonas. A nova sala do Conselho Universitário abrigou, igualmente, por mais de uma década, as reunióes do Seminário de Tropicologia, “órgão de altos estudos da UFPE” dirigido por Gilberto Freyre (VERAS, 2018b), intelectual que liderou a campanha midiática de desinformação contra o reitor João Alfredo. Dentre os documentos impressos, registram-se mais de três dezenas de artigos publicados entre os meses de dezembro de 1963 e junho de 1964, o que permite identificar uma modalidade de ação midiática conservadora comumente utilizada pelas forças golpistas para destruir seus adversários políticos e culturais. Campanhas como essas se estendiam nos meios intelectuais, artísticos e comunicativos, como o rádio, o cinema e a televisão, promovendo os referidos "perceptos" e "afectos" (DELEUZE; GUATTARI, 1992) paranoicos no torvelinho caótico de corpos e de convicçóes anticomunistas, moralistas e outras intolerâncias.

Enquanto isso, no tempo presente, uma nova avalanche de "terrorismo cultural" assalta a universidade e a educação brasileira. Projetos políticos, como o "escola sem partido" e as "escolas cívico-militares", ameaçam hoje os princípios constitucionais de "liberdade de aprender, ensinar, pesquisar e divulgar o pensamento, a arte e o saber" e o "pluralismo de ideias e de concepçóes pedagógicas" (BRASIL, 1988). Também se observa com preocupação as tentativas de distorcer a legislação que rege o exercício constitucional de gestão democrática nas universidades e no ensino público através da intervenção nos processos de escolha de reitores e de demais dirigentes universitários e escolares. O suicídio do professor Luiz Carlos Cancellier de Olivo, reitor da Universidade Federal de Santa Catarina (UFSC), em 2 de outubro de 2017, após ser preso, interrogado e afastado injustamente pela "Operação ouvidos moucos", depois arquivada por falta de provas, reacende o sinal de alerta das instituiçóes democráticas e a importância das histórias e das memórias sobre a apropriação autoritária do Estado e da mídia em detrimento das pessoas e da vida. 
Afinal, como ensina Walter Benjamin, "articular historicamente o passado [...] significa apropriar-se de uma reminiscência, tal como ela relampeja no momento de um perigo" (BENJAMIN, 1994, p. 224), assim alertando para as forças que ameaçam a existência e despertando no pretérito as centelhas de esperanças presente e futura.

\section{Fontes primárias}

ALCÂNTARA, Marcos Aurélio. Informativo Econômico. Diário de Pernambuco, 19 dez. 1963, p. 4. No original do jornal o autor assina "M.A.A.".

ALCÂNTARA, Marcos Aurélio. Informativo Econômico. Diário de Pernambuco, 24 dez. 1963, p. 4.

ALCÂNTARA, Marcos Aurélio. Informativo Econômico. Diário de Pernambuco, 1 jan. 1964, p. 4

ALCÂNTARA, Marcos Aurélio. Informativo Econômico. Diário de Pernambuco, 12 jan. 1964, p. 4.

ALCÂNTARA, Marcos Aurélio. Informativo Econômico. Diário de Pernambuco, 16 jan. 1964, p. 4.

ALCÂNTARA, Marcos Aurélio. Informativo Econômico. Diário de Pernambuco, 19 jan. 1964, p. 4.

ALCÂNTARA, Marcos Aurélio. Informativo Econômico. Diário de Pernambuco, 9 fev. 1964, p. 4.

ALCÂNTARA, Marcos Aurélio. Informativo Econômico. Diário de Pernambuco, 15 fev. 1964, p. 4.

ALCÂNTARA, Marcos Aurélio. Informativo Econômico. Diário de Pernambuco, 16 fev. 1964, p. 4.

ALCÂNTARA, Marcos Aurélio. Informativo Econômico. Diário de Pernambuco, 26 fev. 1964, p. 4.

ALCÂNTARA, Marcos Aurélio. Informativo Econômico. Diário de Pernambuco, 10 mar. 1964, p. 4.

ALCÂNTARA, Marcos Aurélio. Informativo Econômico. Diário de Pernambuco, 14 mar. 1964, p. 4.

ALCÂNTARA, Marcos Aurélio. Informativo Econômico. Diário de Pernambuco, 22 mar. 1964, p. 4.

ALCÂNTARA, Marcos Aurélio. Informativo Econômico. Diário de Pernambuco, 3 abr. 1964, p. 4. 
ALCÂNTARA, Marcos Aurélio. Informativo Econômico. Diário de Pernambuco, 3 jun. 1964, p. 10.

ALCÂNTARA, Marcos Aurélio. Informativo Econômico. Diário de Pernambuco, 9 jun. 1964, p. 2, 4.

ALFREDO, João. Esclarecimentos sobre o programa da Rádio Universidade do Recife. Diário de Pernambuco, 22 dez. 1963, p. 9.

ALUNOS de jornalismo vão estagiar na Rádio Universidade e na A. N., Diário de Pernambuco, 26 abr. 1964, p. 14.

BARBOSA, Socorro Ferraz. [Entrevista concedida a] Projeto Marcas da Memória. Projeto Marcas da Memória, 2011. Disponível em: https:/www.youtube.com/channel/UCc_o5ZHJRo3GDtpUqCvvXg. Acesso em: 12 jul. 2019.

BRASIL. [Constituição (1988)]. Constituição da República Federativa do Brasil de 1988. Brasília: Presidência da República, 2016. Disponível em: http://www.planalto.gov.br/ ccivil_03/constituicao/constituicao.htm. Acesso em: 15 ago. 2019.

BRASIL. Comissão Nacional da Verdade. v. 1. Brasília: CNV, 2014a. Disponível em: http:// cnv.memoriasreveladas.gov.br/index.php. Acesso em: 26 jan. 2018.

BRASIL. Comissão Nacional da Verdade. v. 2. Brasília: CNV, 2014b. Disponível em: http:// cnv.memoriasreveladas.gov.br/index.php. Acesso em: 26 jan. 2018.

BRASIL. Comissão Nacional da Verdade. v. 3. Brasília: CNV, 2014c. Disponível em: http:// cnv.memoriasreveladas.gov.br/index.php. Acesso em: 26 jan. 2018.

CASTELO recebeu consagradora manifestação. Diário de Pernambuco, 6 jun. 1964, p. 1.

ESTAVA integrado na ação subversiva. Diário de Pernambuco, 5 mai. 1964, p. 8.

FORÇAS Armadas tem objetivo de descomunizar país. Diário de Pernambuco, 7 abr. 1964, p. 3.

FREYRE, Gilberto. Um bom exemplo russo-soviético. Diário de Pernambuco, 1 mar. 1964, p. 4.

FREYRE, Gilberto. O caso da Universidade do Recife. Diário de Pernambuco, 3 mai. 1964, p. 4.

FREYRE, Gilberto. Justiça revolucionária e universidade. Diário de Pernambuco, 19 jun. 1964 , p. 4.

FREYRE, Gilberto. Uma responsabilidade inconfundível. Diário de Pernambuco, 17 mai. 1964 , p. 4.

FREYRE, Gilberto. Limpeza urgente. Diário de Pernambuco, 26 mai. 1964, p. 3.

FREYRE, Gilberto. Ainda a propósito da universidade. Diário de Pernambuco, 7 jun. 1964, p. 4 . 
FREYRE, Gilberto. Em torno da resposta de um reitor. Diário de Pernambuco, 11 jun. 1964, p. 4.

MAC DOWELL, Maria Antônia. [Entrevista concedida a Evson Malaquias Santos]. In: SANTOS, Evson Malaquias (org.). UFPE: Instituição, gestão, política e seus bastidores. Recife: UFPE, 2012.

MOREIRAS, Palhares Reis. [Entrevista concedida a Evson Malaquias Santos]. In: SANTOS, Evson Malaquias (org.). UFPE: Instituição, gestão, política e seus bastidores. Recife: UFPE, 2012.

PERISCÓPIO. Diário de Pernambuco, 5 mai. 1964, p. 2.

PERNAMBUCO. Comissão Estadual de Memória e Verdade Dom Helder Câmara: relatório final. V. 1 e 2. Recife: CEPE, 2017a; 2017b.

RÁDIO Universidade tem novos critérios: integração da UR. Diário de Pernambuco, 19 abr. 1964, p. 3.

REITOR diz que encontrou em Brasília tranquilidade, esperança e confiança. Diário de Pernambuco, 3 mai. 1964, p. 10.

REITOR defende-se de críticas à sua atuação na UR. Diário de Pernambuco, 5 mai. 1964, p. 3. REITOR João Alfredo responde a artigo de Gilberto Freyre. Diário de Pernambuco, 10 jun. 1964, p. 2, 16.

UNIVERSIDADE DO RECIFE. Atas do Conselho Universitário da Universidade do Recife. Recife: UR, 12 mar. 1964.

UNIVERSIDADE DO RECIFE. Comissöes de Inquérito. Comissão para apurar responsabilidade de servidores docentes/administrativos (Art. $8^{\circ}$ do Ato Institucional). Recife: UR, 12 jun. 1964.

UNIVERSITÁRIOS estranham permanência do reitor. Diário de Pernambuco, 25 abr. 1964, p. 4.

\section{Referências}

ABREU, Alzira Alves de et al (coord.). Dicionário histórico-biográfico brasileiro - Pós 1930. Rio de Janeiro: CPDOC, 2010. Disponível em: http://fgv.br/cpdoc/acervo/dicionarios/ verbete-biografico/antonio-cavalcanti-neves. Acesso em: 20 mai. 2020.

BATISTA NETO, José. MCP: O Povo como categoria Histórica. In: REZENDE, A. P. Recife: Que História é essa?. Recife: Fundação de Cultura Cidade do Recife, 1987.

BENJAMIN, Walter. Magia e técnica, arte e politica: ensaios sobre literatura e história da cultura. 7. ed. São Paulo: Brasiliense, 1994. 
BOURDIEU, Pierre. A economia das trocas simbólicas. 6. ed. São Paulo: Perspectiva, 2007. BOURDIEU, Pierre. Homo Academicus. 2. ed. Florianópolis: UFSC, 2013.

BRAYNER, Nadja Maria Miranda; BARBOSA, Maria do Socorro Ferraz. Graves violaçóes dos direitos humanos nos meios educacionais culturais. In: PERNAMBUCO. Comissão Estadual de Memória e Verdade Dom Helder Câmara: relatório final. V. 2. Recife: CEPE, 2017.

CÉSAR, Ana Maria. A faculdade sitiada. Recife: CEPE, 2009.

CHARLE, Christophe. La republique des universitaires, 1870-1940. Paris: Le Seuil, 1994.

CHARLE, Christophe. Homo historicus: reflexôes sobre história, os historiadores e as ciências sociais. Porto Alegre: UFRGS; Rio de Janeiro: FGV, 2018.

CUNHA, Luiz Antônio. A universidade crítica: o ensino superior na república populista. 3. ed. São Paulo: UNESP, 2007.

DELEUZE, Gilles; GUATTARI, Félix. O que é filosofia?. Rio de Janeiro: 34, 1992.

DELEUZE, Gilles; GUATTARI, Félix. Mil Platôs: capitalismo e esquizofrenia. v. 4; São Paulo: 34, 1997.

DREIFUSS, René Armand. 1964: a conquista do Estado. Ação política, poder e golpe de classe. 2. ed. Petrópolis: 1981.

FERREIRA, Jorge; GOMES, Ângela de Castro. 1964: o golpe que derrubou um presidente, pôs fim ao regime democrático e instituiu a ditadura no Brasil. Rio de Janeiro: Civilização Brasileira, 2014.

FICO, Carlos. Além do golpe: versóes e controvérsias sobre 1964 e a Ditadura Militar. Rio de Janeiro: Record, 2004.

GASPARI, Elio. A ditadura envergonhada. 2. ed. Edição digital. Rio de Janeiro: Intrínseca, 2014.

GREEN, Eliot. What are the most-cited publications in the social sciences (according to Google Scholar)?, 2016. Disponível em: https://blogs.lse.ac.uk/impactofsocialsciences/2016/05/12/ what-are-the-most-cited-publications-in-the-social-sciences-according-to-google-scholar/. Acesso em: 4 jul. 2019.

GOMES, Luís Eduardo. MEC ignora resultado eleitoral e nomeia reitores temporários para institutos federais em SC e no RN. Sul 21, 20 abr. 2020. Disponível em: https://www. sul21.com.br/ultimas-noticias/politica/2020/04/mec-ignora-resultado-eleitoral-e-nomeiareitores-temporarios-para-institutos-federais-em-sc-e-no-rn/. Acesso em: 15 mai. 2020.

MORENO, Ana Carolina. Governo interveio em 6 de 12 nomeaçóes de reitores de universidades federais até agosto. G1, 31 ago. 2019. Disponível em: https://g1.globo.com/ educacao/noticia/2019/08/31/governo-interveio-em-6-de-12-nomeacoes-de-reitores-deuniversidades-federais-ate-agosto.ghtml. Acesso em: 24 set. 2019. 
MOTTA, Rodrigo Patto Sá. Em guarda contra o perigo vermelho: o anticomunismo no Brasil (1917-1964). Tese (Doutorado em História Econômica) - Programa de Pós-Graduação em História Econômica, Universidade de São Paulo, São Paulo, 2000.

MOTTA, Rodrigo Patto Sá. As universidades e o regime militar. Rio de Janeiro: Zahar, 2014. OPEN SYLLABUS. Open Syllabus Project, 2020. Disponível em: https://opensyllabus.org/ results-list/titles?size $=50$. Acesso em: 8 abr. 2020.

PERRUCI, Gadiel. Um projeto oligárquico-liberal de universidade (notas para uma história da UFPE). Cadernos de Estudos Sociais, Recife, v. 2, n. 2, 1986.

ROLLEMBERG, Denise; QUADRAT, Samantha Viz (org.). A construção social dos regimes autoritários. Legitimidade, consenso e consentimento no século XX. Brasil e América Latina. v. 2. Rio de Janeiro: Civilização brasileira, 2010.

ROSAS, Paulo. Recife: cultura e participação. In: FREIRE, Paulo. Educação e atualidade brasileira. 3. ed. São Paulo: Cortez; Instituto Paulo Freire, 2003.

SANTOS, Evson Malaquias (org.). UFPE: instituição, gestão, política e seus bastidores. Recife: UFPE, 2012.

SANTOS, Francisco Sá Barreto dos. A construção do fato pelo discurso midiático. $\mathrm{O}$ caso do atentado a bomba no Aeroporto. Dissertação (Mestrado em Comunicação) - Programa de Pós-Graduação em Comunicação, Universidade Federal de Pernambuco, Recife, 2007.

SILVA JUNIOR, Edelson de Albuquerque. O reitorado de João Alfredo na Universidade do Recife-UR (1959-1964): patrimonialismo populista e modernização científica. Dissertação (Mestrado em Educação) - Programa de Pós-Graduação em Educação, Universidade Federal de Pernambuco, Recife, 2012.

SOUZA, Maria Inêz Salgado de. O IPES e a política educacional após 1964. Petrópolis: Vozes, 1981.

TEIXEIRA, Flavio Weinstein. O movimento e a linha: presença do Teatro do Estudante e d'O Gráfico Amador no Recife (1946-1964). Recife: UFPE, 2007.

VERAS, Dimas Brasileiro. Sociabilidades letradas no Recife: a revista Estudos Universitários (1962-1964). Recife: UFPE, 2012.

VERAS, Dimas Brasileiro. Onde dorme o cão sem plumas: o Recife e a formação do Sistema Paulo Freire de Educação. In: SANTIAGO, Eliete; BATISTA NETO, José (org.). Paulo Freire e a educação libertadora: memórias e atualidades. Recife: UFPE, 2013.

VERAS, Dimas Brasileiro. Rádio Universidade: uma rádio a serviço da democratização da cultura. In: GOMES, Margarita Victoria (org.). Círculo de cultura Paulo Freire: arte, mídia e educação. São Paulo: Fundação Memorial da América Latina, 2015. (Livro Eletrônico). Disponível em: http://www.ccm.ufpb.br/redepopsaude/wp-content/uploads/2016/06/ CirculoDeCulturaPauloFreire_ArteMidiaEducacao.pdf. Acesso em: 2. jul. 2019. 
VERAS, Dimas Brasileiro. A universidade em debate nas páginas da Estudos Universitários (1962-1969). Estudos Universitários, revista de cultura. v. 33. n. 1 e 2. Recife: UFPE, 2016. VERAS, Dimas Brasileiro. Educação popular como práxis da extensão para uma revolução na educação profissional e tecnológica. Revista Práxis: saberes da extensão, [S. 1.], v. 4, n. 5, p. 107-112, fev. 2018a. Disponível em: http://periodicos.ifpb.edu.br/index.php/praxis/ article/view/849. Acesso em: 2 jul. 2019.

VERAS, Dimas Brasileiro. Palácios cariados: a elite universitária e a ditadura militar - o caso da Universidade Federal de Pernambuco (1964-1975). Tese (Doutorado em História) - Programa de Pós-Graduação em História, Universidade Federal de Pernambuco, Recife, 2018b. 